\title{
A New Surface-Inset, Permanent-Magnet, Brushless DC Motor Drive for Electric Vehicles
}

\author{
Jinyun Gan, K. T. Chau, Member, IEEE, C. C. Chan, Fellow, IEEE, and J. Z. Jiang
}

\begin{abstract}
A new five-phase, surface-inset, permanent-magnet $(\mathrm{PM})$, brushless dc motor drive is proposed in this paper. The motor drive has advantages of both the PM brushless dc motor drive and the dc series motor drive. The originlity is that the air-gap flux of the motor is generated by both the PM excitation and the specially controlled stator currents (two particular phases) under the same PM pole. The motor configuration and principle of operation are so unusual that the magnetic field distribution and steady-state performance are analyzed by the finite-element method (FEM). Experimental results for a prototype verify that the proposed motor drive is promising for modern electric vehicle applications.
\end{abstract}

Index Terms-Brushless dc motors, electric vehicles, motor drives, permanent magnet motors.

\section{INTRODUCTION}

$\mathbf{I}$ $\mathrm{N}$ A world in which environment protection and energy conservation are growing concerns, the development and commercialization of electric vehicles (EVs) have taken on an accelerated pace to fulfill these needs. The drive system, including motor and its controller, is the heart of EVs. For EV motor drives, both high-torque, low-speed hill climbing and low-torque, high-speed cruising are desirable. Thus, the torque-speed characteristic of dc series motors should be most attractive for EV propulsion. However, owing to the drawbacks of low efficiency, low-power density, as well as the need of mechanical commutator and carbon brushes, dc series motors are being superseded by induction motors and permanent-magnet (PM), brushless motors. As the PM brushless motor drives have distinct advantages of high efficiency, high-power density, and maintenance-free operation, they have been identified as the most promising drive system for modern EVs [1]. However, the main problem with this drive system is its limited speed range for constant power operation. It is because the PM brushless motor generally suffers from the difficulties in realizing flux-weakening control that can be easily achieved by properly reducing the field current in dc motors.

In accordance with the current waveform feeding into the motor terminals, PM brushless motor drives can be classified as sinusoidal-fed PM brushless motor drives (also called PM

Manuscript received September 10, 1999; revised May 8, 2000. This work was supported by a grant from the Research Grants Council of the Hong Kong Special Administrative Region, China.

J. Gan, K. T. Chau, and C. C. Chan are with the Department of Electrical and Electronic Engineering, University of Hong Kong, Hong Kong, China (e-mail: jygan@eee.hku.hk; ktchau@eee.hku.h; ccchan@eee.hku.hk).

J. Z. Jiang is with School of Automation, Shanghai University, Shanghai 200072, China (e-mail: jzhjiang@yc.shu.edu.cn).

Publisher Item Identifier S 0018-9464(00)08677-5. synchronous motor drives or PM brushless ac motor drives) and rectangular-fed PM brushless motor drives (also called PM brushless dc motor drives). To extend the constant power speed range of these PM brushless motor drives, flux-weakening control has been developed in recent years. It is essentially a current vector control based on $d$-q-coordinate transformation [2]-[7]. When they operate above the base speed, the $d$-axis (aligned with the center of the PM pole) component of stator current is controlled to weaken the air-gap flux produced by the PM. Because the permeability of PM material is nearly equal to that of air, a high $d$-axis demagnetizing current is usually required to obtain the flux-weakening effect at high speeds. This increases the copper losses and decreases the efficiency of these motor drives. In addition, an excessive $d$-axis current has a risk of demagnetizing the PM material irreversibly [7]. Thus, the maximum achievable speed is limited by the constraints of the inverter current and voltage as well as the maximum allowable demagnetizing current of the PM material. Nevertheless, by optimal design of the motor parameters, such as open circuit voltage, $d$-axis armature reactance, and $q$-axis armature reactance, the speed range of PM synchronous motor drives can be extended considerably [3]-[7], but by sacrificing the utilization of inverters [4], [6].

As flux-weakening control needs $d$ - $q$-coordinate transformation, it is ill-suited for the rectangular-fed PM brushless dc motors. Although the rectangular wave can be expressed into fundamental and harmonic sinusoidal waves by using Fourier analysis, it is too cumbersome to be realized in real-time control. Because the interaction between rectangular flux and rectangular current in the motor can produce higher torque product than that produced by sinusoidal flux and sinusoidal current [9]-[11], PM brushless dc motor drives inherently possess higher power density than do PM synchronous motor drives. Recently, a control scheme, namely, advanced conduction angle control, has been developed that can significantly extend the constant power operating range of $\mathrm{PM}$ brushless dc motor drives. Its concept is to purposely employ the transformer EMF to counteract the rotational EMF at high speeds. As this approach does not need any coordinate transformation, it is easy to be realized in real time [9].

Instead of developing control approaches to extend the constant power operating range of conventional PM brushless dc motor drives, the purpose of this paper is to present a new PM brushless dc motor drive with a unique feature of flux regulation. Thus, it can incorporate the advantages of high-power density and high efficiency of a PM brushless dc motor drive as well as the advantages of high starting torque and the wide constant power operating range of a dc series motor drive for EV propulsion. The key originality is that the air-gap flux of this motor 
is generated by both the PM excitation and the specially controlled stator currents (two particular phases) under the same PM pole. Hence, the torque of the motor is composed of two parts. One part is the PM torque produced by interaction between the PM excitation and the two-phase stator currents. Another part is the electromagnetic torque produced by interaction between the magnetic field generated by the two-phase stator currents and the stator currents of other phases. As this part of torque is approximately proportional to the square of phase current, it offers the characteristics of a dc series motor. Therefore, this new motor drive possesses advantageous characteristics of both the PM brushless dc motor drive and the dc series motor drive.

In Section II, the theory of operation of this new PM brushless dc motor drive will be introduced. It will be devoted to describing the corresponding configuration, operation, and model. The electromagnetic field analysis will be described in Section III. The steady-state performance of the proposed motor drive will be discussed in Section IV. Experimental results will be given in Section V to verify the theoretical analysis. Finally, a conclusion will be drawn in Section VI to summarize the advantages of the proposed motor drive for EV propulsion.

\section{THEORY OF OPERATION}

\section{A. Motor Configuration}

In 1985, the concept of the inverter-fed multiphase reluctance motor was introduced [11], [12]. Then, the corresponding design details and performance analysis were carried out in 1994 [13]. The basic principle of operation of this motor is similar to that of the dc motor, except that both the field windings and the armature windings are located in the stator. As shown in Fig. 1(a), its stator windings simultaneously operate as both the field windings and the armature windings. The stator current of particular phases located under the pole faces acts as the armature current $i_{a}$ (hence, producing the armature reaction field $F_{a}$ ), whereas the stator current of other phases located in the interpole area acts as the field current $i_{f}$ (hence, producing the field excitation $F_{f}$ ). When the motor runs, each phase winding carries either $i_{a}$ or $i_{f}$, depending on the rotor position. Because each phase current of this multiphase reluctance motor can be individually controlled by using a multiphase inverter, both $i_{a}$ and $i_{f}$ can be independently controlled, hence, offering the characteristics of the dc motor. Also, the rectangular current and field distributions enable this motor to have the feature of high-power density [11]-[13].

With further investigation into this multiphase reluctance motor, it can be discovered that when the positive torque $T_{a}$ is produced by the interaction between $i_{a}$ and $F_{f}$, there is an undesirable negative torque $T_{f}$ generated by the interaction between $i_{f}$ and $F_{a}$. Thus, an idea is born, namely, the utilization of the stator field current to produce a positive torque. By properly inserting PM material in the sunken space of the rotor surface as shown in Fig. 1(b), it creates two positive torque components. One is the reluctance torque $T_{r}=\left(T_{a}-T_{f}\right)$, where $T_{a}$ is due to the interaction of $i_{a}$ and $F_{f}$, while $T_{f}$ is due to the interaction of $i_{f}$ and $F_{a}$. Another is the PM torque $T_{m}$

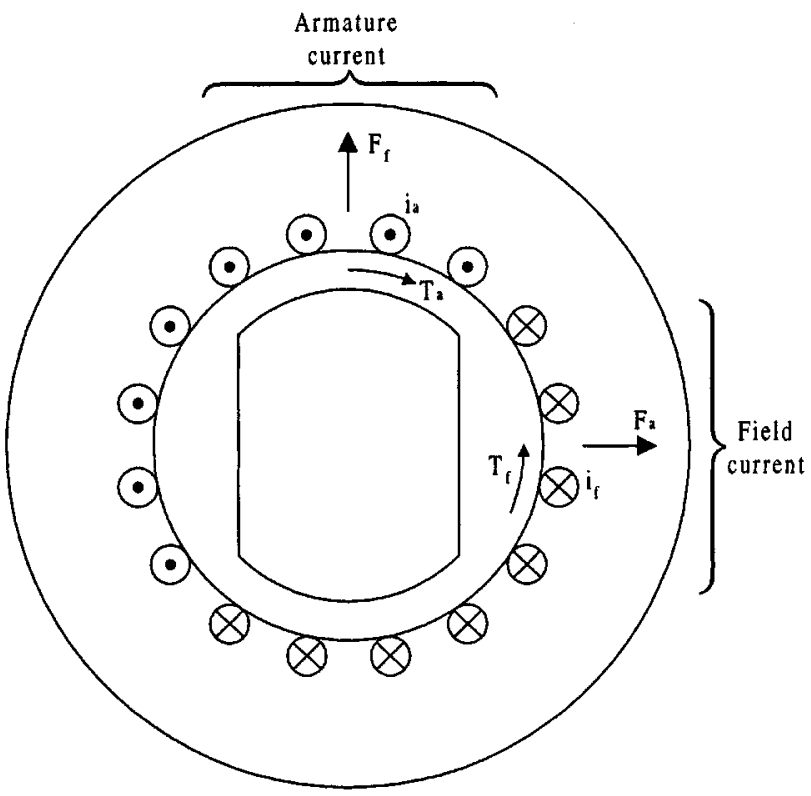

(a)

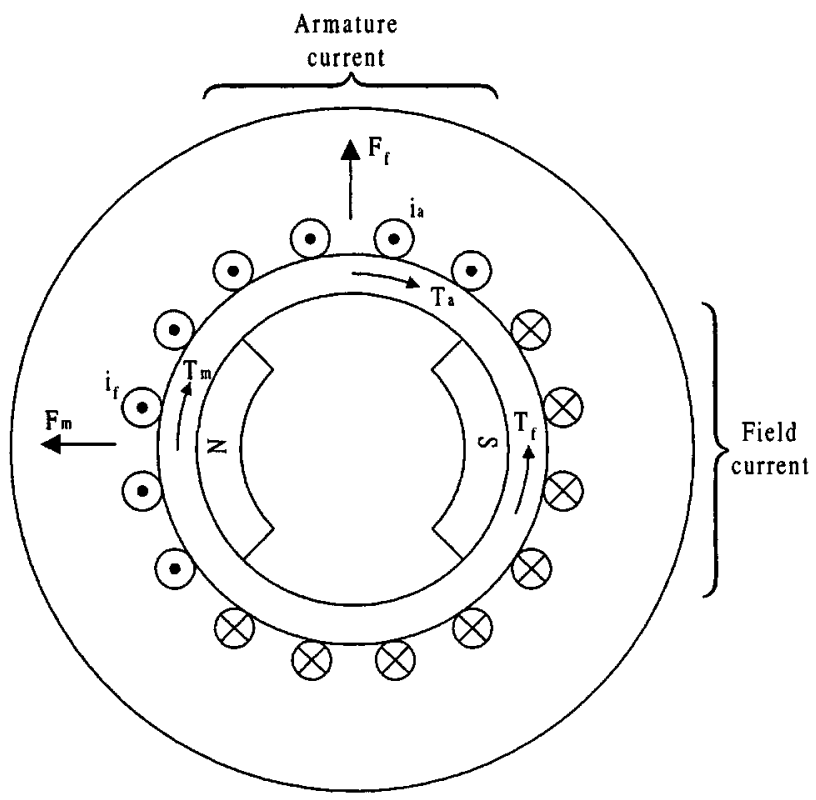

(b)

Fig. 1. Simplified motor configurations: (a) multiphase reluctance motor and (b) multiphase surface-inset PM brushless dc motor.

due to the interaction of the PM field $F_{m}$ and $i_{f}$. Hence, the power density of this new motor can be further improved.

As a practical realization of the proposed idea, a five-phase, six-pole, surface-inset, PM brushless dc motor is shown in Fig. 2. There are 30 slots in the stator. Each phase has two 


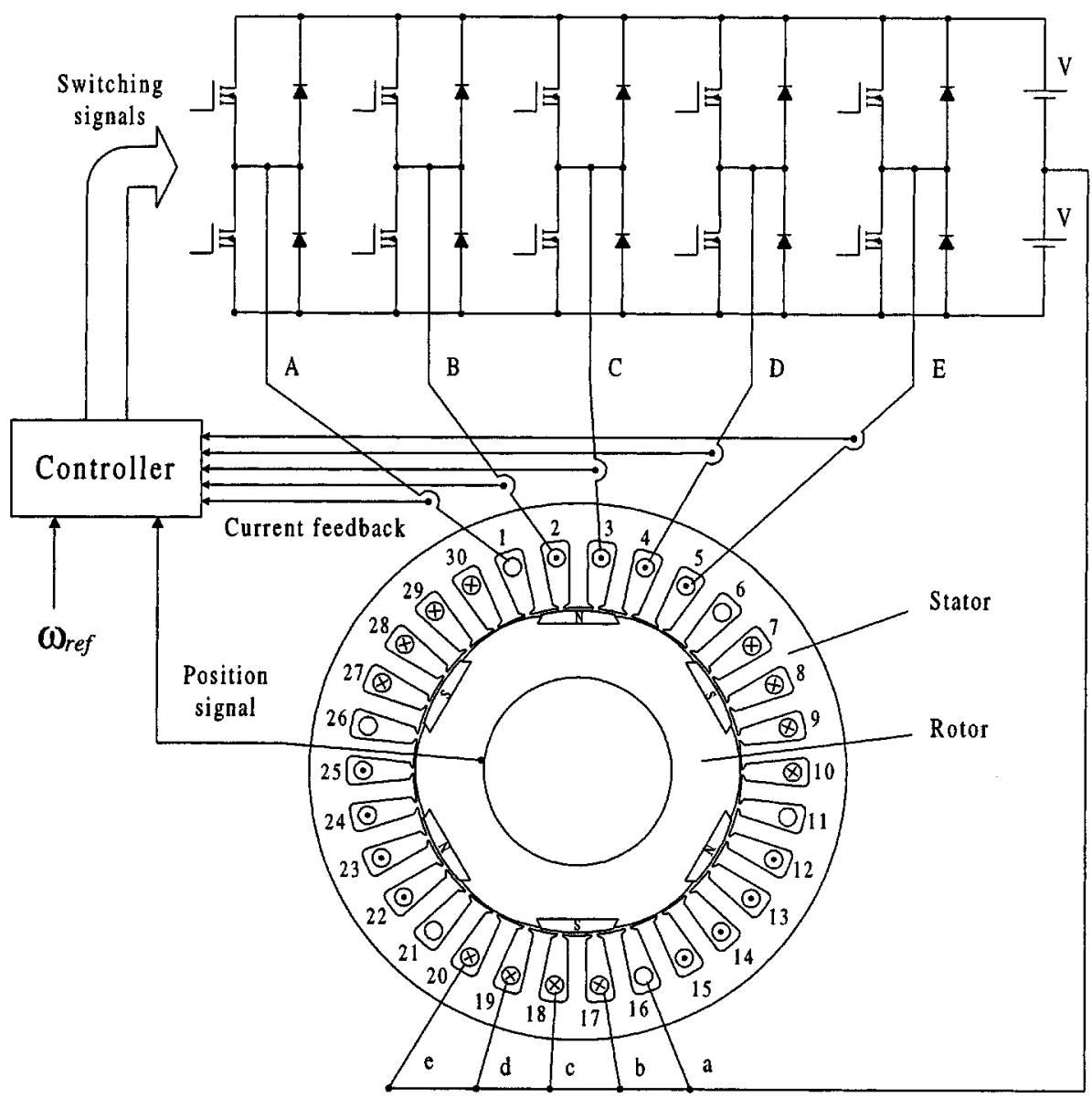

Fig. 2. Five-phase six-pole surface-inset PM brushless dc motor.

slots to form a full-pitch coil under one pair of poles. For three pairs of poles, each phase has three coils. These three coils are connected in series to form a phase winding. Namely, three coils of phase A are, respectively, located in the slots 1 and 6 , the slots 11 and 16, as well as the slots 21 and 26 . There are six PM poles inserted beneath the rotor surface, so-called the surface-inset type. The width of the PM poles is about 2 slot-pitch or $2 / 5$ pole-pitch. Thus, as compared with the conventional surface-mounted type, this motor can significantly save PM material and, hence, reduce the cost. Moreover, as shown in Fig. 3, the dove-tailed shape of these PM poles can improve the mechanical robustness of the rotor during high-speed operation.

To maximize the air-gap flux and, hence, the power density, the air-gap length under the salient core of the rotor should be as short as possible. However, if the air-gap length is too short, the stator current located under the salient core (so-called the armature current) will deform the distribution of the electric excitation field, namely, strengthening the field at the leading edge of the salient core and weakening the field at the lagging edge. Because of the nonlinear magnetizing property of the iron core, magnetic saturation results in decreasing the air-gap flux. This armature reaction is detrimental to the power density, especially the torque capability under short-time overload. In order to reduce the effect of armature reaction while maintaining high air-gap flux density under the salient rotor core, it

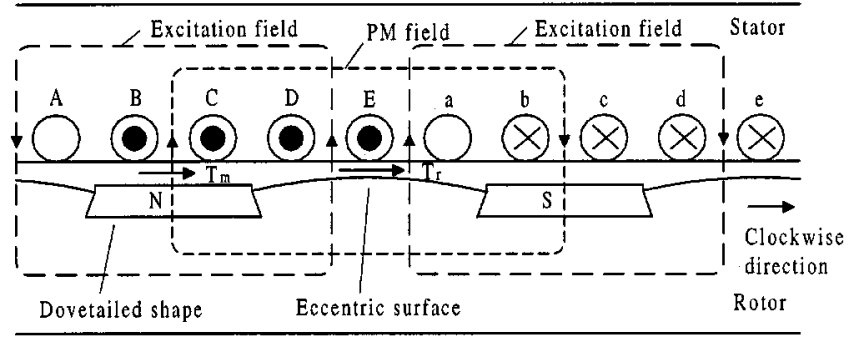

(a)

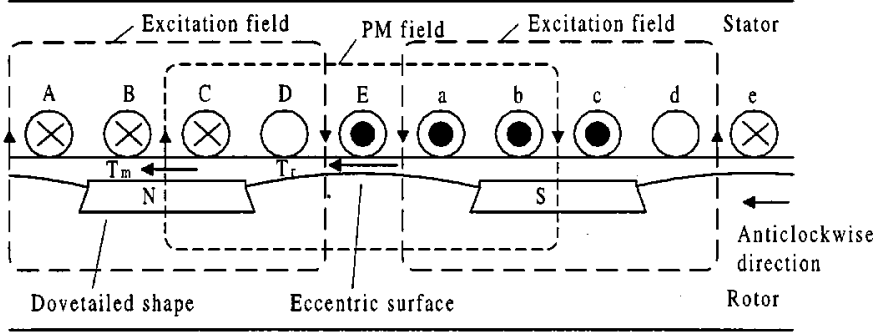

(b)

Fig. 3. Close-up diagram of one pair of poles: (a) clockwise rotation and (b) anticlockwise rotation.

is purposely designed to have an eccentric surface, as shown in Fig. 3, namely, a narrow air gap in the central part of the salient core, whereas an enlarged air gap in the edges. 


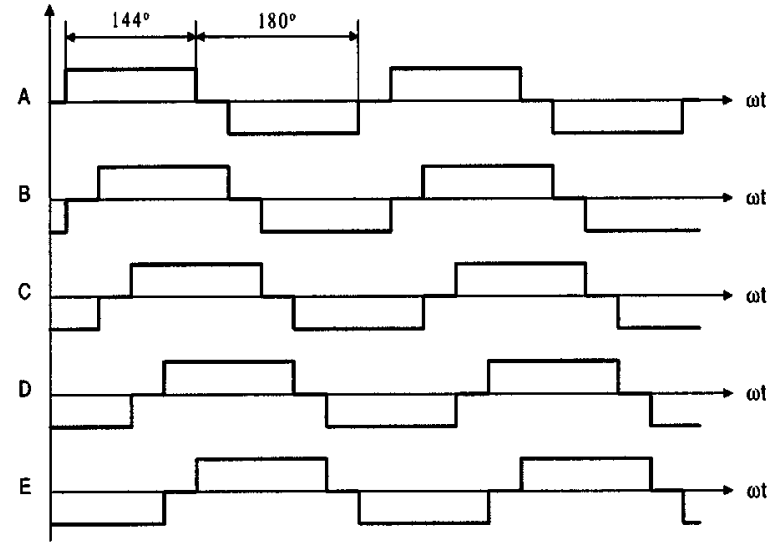

(a)

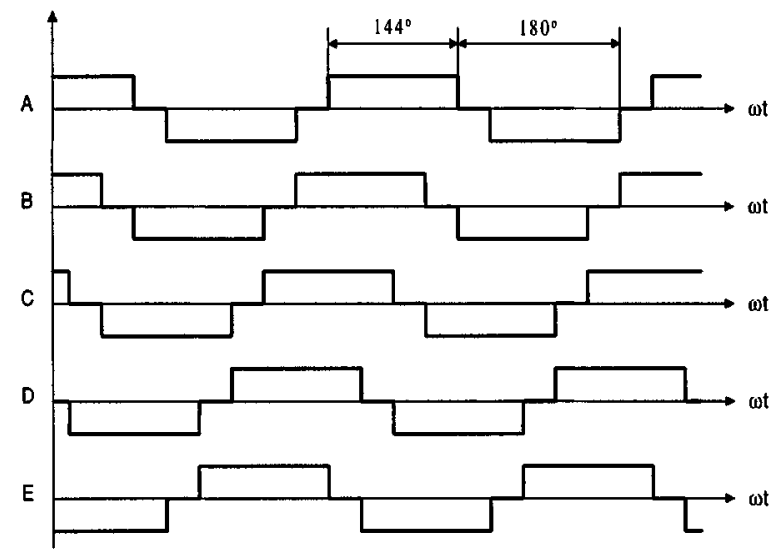

(b)

Fig. 4. Conduction waveforms: (a) clockwise rotation and (b) anticlockwise rotation.

Based on the rotor configuration, the newly proposed motor is a new kind of PM brushless dc motor. Although it seems to be similar to a traditional surface-inset PM brushless ac motor [5], [14], [15], they are actually very different. First, their operating principles are fundamentally different-the proposed motor is fed by multiphase rectangular waves to provide the feature of high power density. Secondly, their rotor configurations are significantly different - the PM width of the proposed motor is purposely less than one-half of the pole pitch to perform field regulation for constant power operation at high speeds, and the salient rotor poles are of eccentric surfaces to reduce the undesirable armature reaction.

\section{B. Motor Operation}

Fig. 4(a) shows the conduction waveforms of all phase windings during clockwise rotation. At any instant, there are four phase windings in the conducting state and one phase winding in the nonconducting state or commutating state. Each phase winding conducts for $144^{\circ}$, and it remains nonconducting for $36^{\circ}$ in each half-cycle. The phase shift between any adjacent phases is $36^{\circ}$. When the rotor position is as shown in Fig. 2, phase $A$ is in a nonconducting state. The current directions of other phases are labeled in the corresponding slots. To illustrate the principle of operation, Fig. 3(a) shows the generation of two torque components for clockwise rotation. It can be seen that only phase $B$ and phase $C$ are located under the PM pole, whereas other phases are located under the salient core of the rotor. Thus, the PM pole provides an excitation field only for the currents of phase $B$ and phase $C$. The interaction between them generates a driving torque on the rotor like a conventional PM brushless motor. Hence, this torque component is named as the PM torque $T_{m}$. On the other hand, the currents of phase $B$ and phase $C$ also generate an excitation field in the salient core. Then, an electromagnetic torque is generated, which consists of the positive component $T_{a}$ due to the interaction between this excitation field and the armature currents of phase $D$ and phase $E$, and the negative component $T_{f}$ due to the interaction between the armature reaction field and the currents of phase $B$ and phase $C$. Because the principle of this torque production is the same as that of the multiphase reluctance motor, this torque component is named as the reluctance torque $T_{r}=\left(T_{a}-T_{f}\right)$. In order to keep these two torque components in the same direction, the direction of each phase current should be properly set according to the rotor position signal and the rotational direction. When the phase windings are conducted in the sequence shown in Fig. 4(a), the motor continues to rotate clockwise. On the other hand, when the currents of phase $B$ and phase $C$ are reversed as shown in Fig. 3(b), the two torque components produced on the rotor become anticlockwise. Because of the change of rotational direction, phase $A$ should be in the conducting state while phase $D$ is in the nonconducting state. To run the motor continuously, the five-phase conduction waveforms should follow the sequence shown in Fig. 4(b).

As a summary, the air-gap field of the proposed motor consists of two excitation fields, namely, the PM excitation in the rotor and the electric excitation in the stator. The former enables the motor to have an extra PM torque component, hence, higher power density, compared with the multiphase reluctance motor. On the other hand, the latter enables the motor to produce a controllable reluctance torque component that can be regulated by individual control of the phase current. In fact, this reluctance torque component possesses the feature of a dc motor, and it plays an important role in adjustable speed control. For instance, by purposely decreasing the stator current under the PM pole, the electric excitation field diminishes correspondingly so that flux-weakening control can be achieved to extend the constant power speed range.

\section{Motor Model}

The system voltage equation of the proposed motor with $m$-phases can be expressed as

$$
\begin{aligned}
{\left[\begin{array}{c}
v_{1} \\
v_{2} \\
\vdots \\
v_{m}
\end{array}\right]=} & {\left[\begin{array}{llll}
R & & & \\
& R & & \\
& & \ddots & \\
& & & R
\end{array}\right]\left[\begin{array}{c}
i_{1} \\
i_{2} \\
\vdots \\
i_{m}
\end{array}\right] } \\
+ & {\left[\begin{array}{cccc}
L_{11} & L_{12} & \cdots & L_{1 m} \\
L_{21} & L_{22} & \cdots & L_{2 m} \\
\vdots & \vdots & \cdots & \vdots \\
L_{m 1} & L_{m 2} & \cdots & L_{m m}
\end{array}\right] p\left[\begin{array}{c}
i_{1} \\
i_{2} \\
\vdots \\
i_{m}
\end{array}\right] }
\end{aligned}
$$




$$
\begin{aligned}
& +p\left[\begin{array}{cccc}
L_{11} & L_{12} & \cdots & L_{1 m} \\
L_{21} & L_{22} & \cdots & L_{2 m} \\
\vdots & \vdots & \cdots & \vdots \\
L_{m 1} & L_{m 2} & \cdots & L_{m m}
\end{array}\right]\left[\begin{array}{c}
i_{1} \\
i_{2} \\
\vdots \\
i_{m}
\end{array}\right] \\
& +\left[\begin{array}{c}
e_{1} \\
e_{2} \\
\vdots \\
e_{m}
\end{array}\right] .
\end{aligned}
$$

In short form, it is written as

$$
[v]=[R][i]+[L] p[i]+p[L][i]+[e],
$$

where

$[v] \quad$ applied voltage;

$[R][i] \quad$ resistance voltage drop;

$p \quad$ time differential operator;

$[L] p[i] \quad$ transformer EMF;

$p[L][i] \quad$ rotational EMF due to the reluctancy;

[e] rotational back EMF due to the PM material;

$L_{i i} \quad$ self-inductance of phase $i$;

$L_{i j} \quad$ mutual inductance between phase $i$ and phase $j$.

Due to the reluctancy, $p[L]$ is not equal to zero, and it can be expressed as

$$
p[L]=\frac{d}{d \theta}[L] \frac{d \theta}{d t}=\omega \frac{d}{d \theta}[L],
$$

where $\theta$ is the angle between the rotor axis and the stator winding axis and $\omega$ is the angular speed. Hence, the corresponding torque is given by

$$
T_{e}=[i]^{T} \frac{d}{d \theta}[L][i]+[e]^{T}[i] / \omega,
$$

where the first term corresponds to the reluctance torque component and the second term corresponds to the PM torque component.

\section{Electromagnetic Field ANALysis}

Because of nonuniform air gap and multisource air-gap flux, the design of the proposed motor employs electromagnetic field analysis. The corresponding procedure is summarized as follows.

- Initialize the motor configuration and geometry.

- Generate meshes automatically for the region of interest.

- Apply the finite element method (FEM) for electromagnetic field analysis.

- Evaluate the motor parameters and performances.

- Modify the motor geometry iteratively.

\section{A. Finite Element Model}

Because the flux distribution in each cross section is basically identical and the leakage flux at two end regions is negligible, the two-dimensional FEM is used to analyze the electromagnetic field. Due to the symmetric motor configuration, the re- gion of one pair of poles is taken as the interested area. The corresponding Maxwell's equation is expressed as

$$
\frac{\partial}{\partial x}\left(\nu \frac{\partial A}{\partial x}\right)+\frac{\partial}{\partial y}\left(\nu \frac{\partial A}{\partial y}\right)=-J_{z}-\nu \frac{\partial M_{y}}{\partial x}+\nu \frac{\partial M_{x}}{\partial y},
$$

$$
\begin{array}{ll}
\text { where } & \\
A & \text { magnetic vector potential; } \\
J_{z} & \text { current density in } z \text {-direction; } \\
\nu & \text { reluctivity; } \\
M_{x} \text { and } M_{y} & \text { the magnetic polarization in } x \text { - and } y \text {-direc- } \\
& \text { tions, respectively. }
\end{array}
$$

The magnetic flux density $B$ can be obtained as

$$
B=\operatorname{rot} A \text {. }
$$

The corresponding $x$ - and $y$-components are expressed as:

$$
\begin{aligned}
& B_{x}=\frac{\partial A}{\partial y}, \\
& B_{y}=-\frac{\partial A}{\partial x} .
\end{aligned}
$$

Based on the region of interest, the boundary conditions are given by

$$
\begin{aligned}
& \left.A\right|_{T_{1}}=\left.A\right|_{T_{2}}=0, \\
& \left.A\right|_{N_{1}}=\left.A\right|_{N_{2}},
\end{aligned}
$$

where $T_{1}$ and $T_{2}$ are circumferential boundaries and $N_{1}$ and $N_{2}$ are radial boundaries.

Moreover, the electromagnetic force can be calculated by using the Maxwell stress-tensor method. The components of force density on a line parallel to the $x$-axis can be expressed as

$$
\begin{aligned}
f_{x} & =\frac{B_{x} B_{y}}{\mu_{0}}, \\
f_{y} & =\frac{1}{2 \mu_{0}}\left(B_{y}^{2}-B_{x}^{2}\right) .
\end{aligned}
$$

Similarly, the components of force density on a line parallel to the $y$-axis are expressed as

$$
\begin{aligned}
f_{x} & =\frac{1}{2 \mu_{0}}\left(B_{x}^{2}-B_{y}^{2}\right), \\
f_{y} & =\frac{B_{x} B_{y}}{\mu_{0}} .
\end{aligned}
$$

\section{B. Magnetic Field Distribution}

Based on the aforementioned model, electromagnetic field analysis of the proposed motor is carried out. The corresponding magnetic flux distributions are shown in Fig. 5. The no-load flux density distribution shown in Fig. 5(a) indicates the component of a PM excitation field. The component of electric excitation field at full load is shown in Fig. 5(b). This component can be adjusted by changing the currents of two particular phases under the PM poles. The resultant field at full load is shown in Fig. 5(c). 


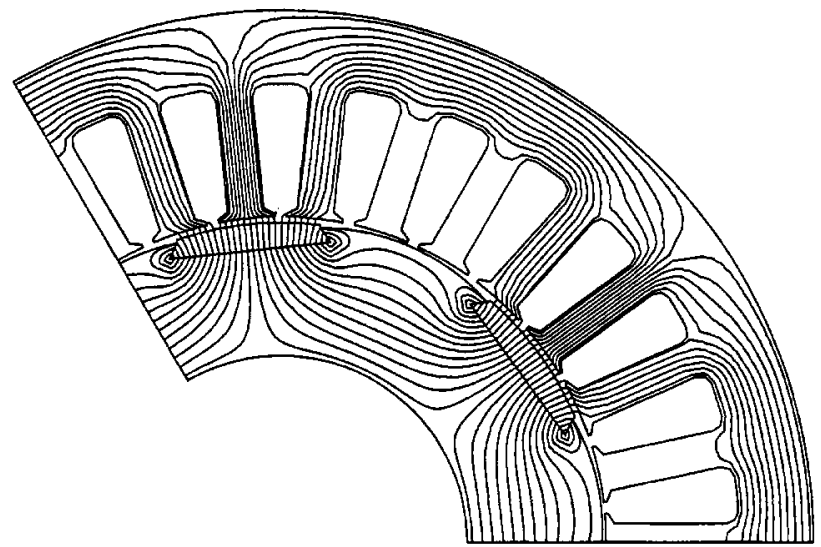

(a)

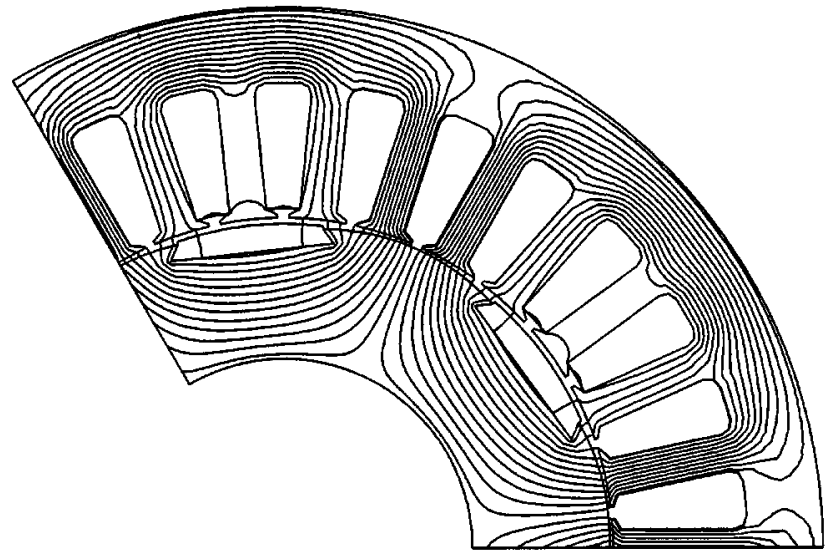

(b)

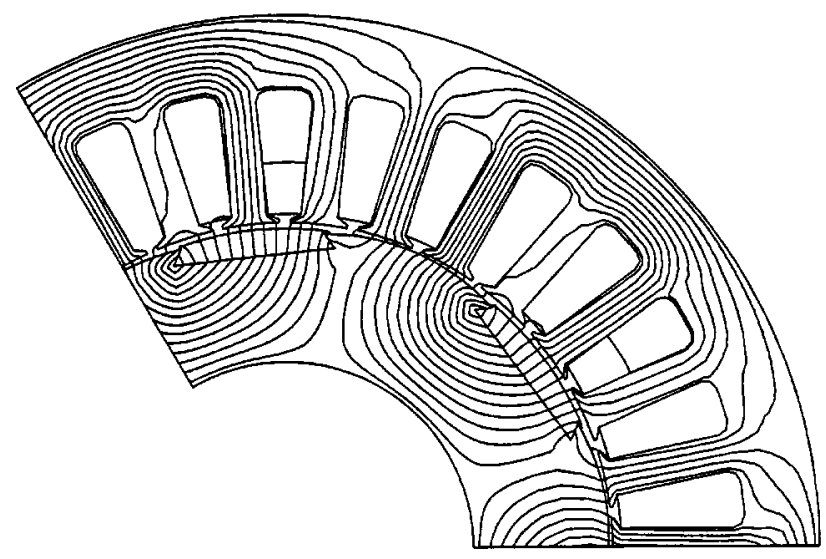

(c)

Fig. 5. Magnetic flux density distribution: (a) PM excitation field, (b) electric excitation field, and (c) full-load resultant field.

\section{Rotational EMF}

In addition to the magnetic flux density distribution, the flux linkage and, hence, the rotational EMF of the phase windings are also determined by using the FEM. The flux passing through a coil is given by

$$
\phi=\left(A_{1}-A_{2}\right) l,
$$

where $A_{1}$ and $A_{2}$ are the magnetic vector potentials of two coil sides that can be directly obtained by the FEM and $l$ is the axial length of the core. Hence, by using Fig. 5(a) and (15), the flux

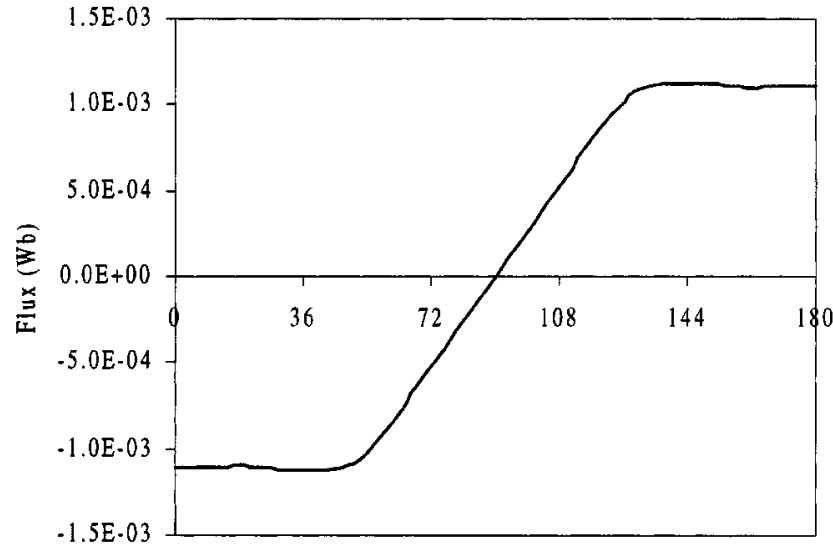

Rotor angle (elect. degree)

(a)

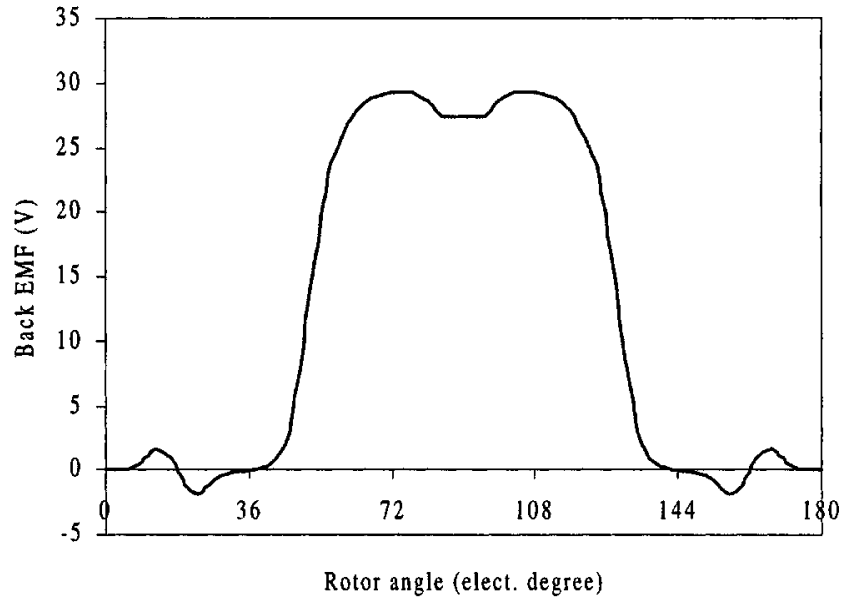

(b)

Fig. 6. No-load characteristics: (a) flux and (b) back EMF.

due to PM excitation that links with a phase winding can be calculated. Based on similar calculations at different rotor positions, the curve of the no-load flux versus the rotor position angle can be obtained as shown in Fig. 6(a). It should be noted that the $0^{\circ}$ corresponds to the position of the PM pole located at the center of the coil. The flat top of the curve is due to the fact that the width of the PM pole is only about $2 / 5$ pole-pitch.

Because each phase has one full-pitch coil under each pair of poles, the flux linkage of each phase winding is given by

$$
\lambda=N \phi,
$$

where $N$ is the number of turns of each phase winding in series. When the motor runs at an angular speed of $\omega$, a back EMF, namely, the rotational EMF, is induced in the phase winding by the PM excitation field. Based on the Faraday law and then using (16), this back EMF can be expressed as

$$
e=\frac{d \lambda}{d \theta} \frac{d \theta}{d t}=\frac{d \lambda}{d \theta} \omega=\omega N \frac{d \phi}{d \theta}
$$

where $\theta$ is the angle between the PM excitation field and the phase winding, which is actually the rotor angle defined in Fig. 6(a). So, $d \phi / d \theta$ can be easily obtained from Fig. 6(a) by simple differentiation. Hence, by using Fig. 6(a) and (17), the back EMF at the base speed of $1000 \mathrm{rpm}$ can be deduced as 


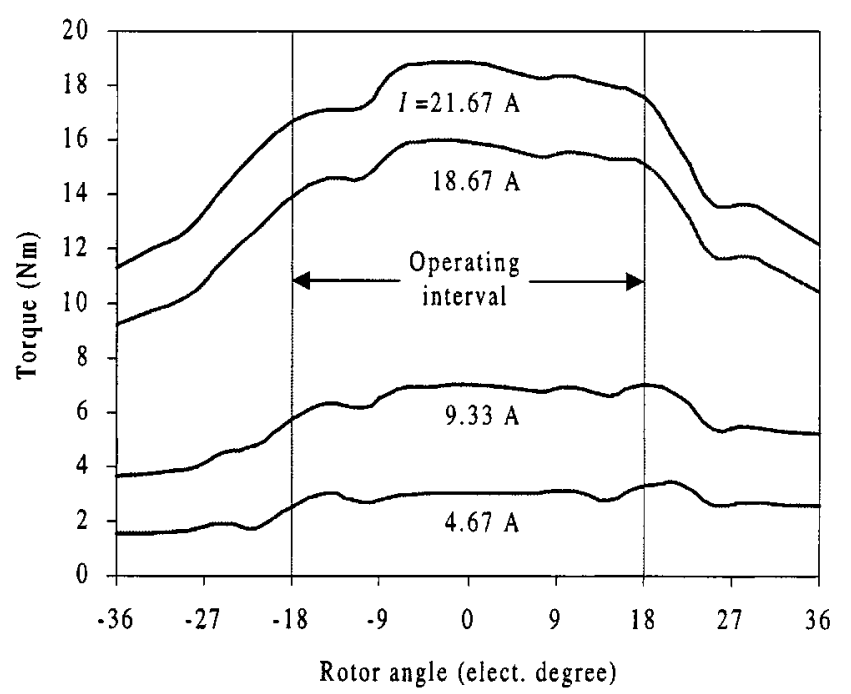

(a)

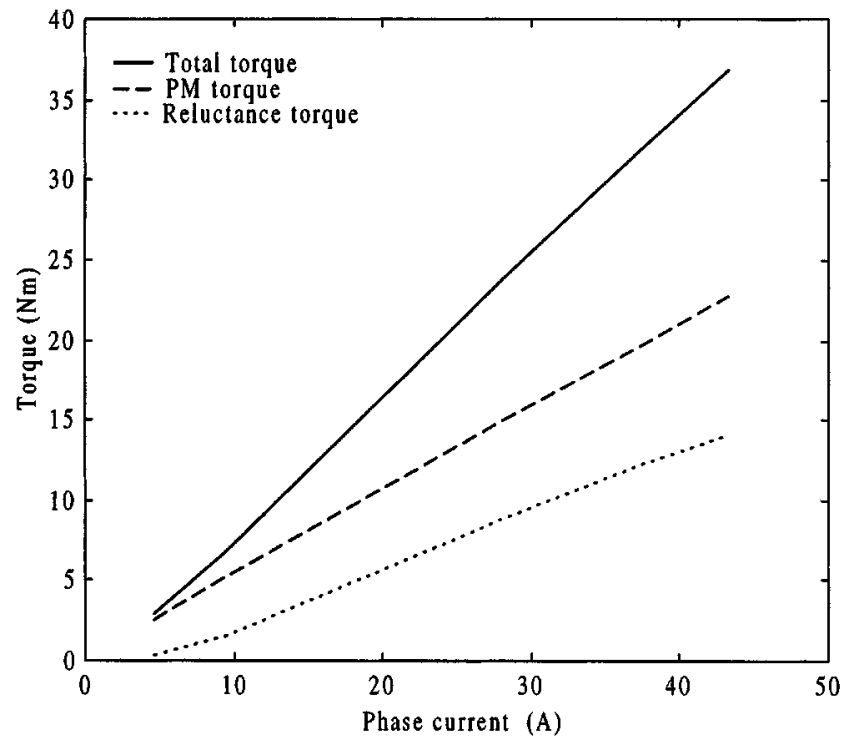

(b)

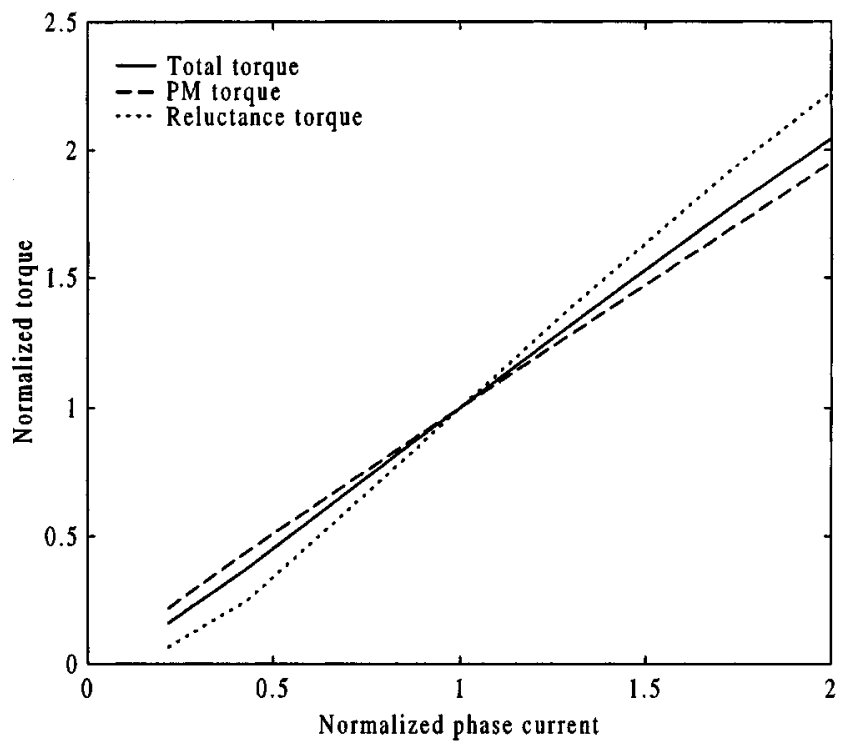

(c)

Fig. 7. Torque characteristics: (a) torque versus rotor position, (b) torque versus current, and (c) normalized torque versus normalized phase current.

shown in Fig. 6(b). It should be noted that this base speed is designed to drive an electric motorcycle with a reduction gear ratio of 3.75 .

\section{Steady-State Performance}

From the principle of operation, the air-gap flux of the proposed motor consists of the PM excitation field and the electric excitation field. The former is fixed, whereas the latter varies with the stator phase current. Thus, the steady-state characteristic of torque versus rotor position changes with the phase current $I$ as shown in Fig. 7(a), in which the $0^{\circ}$ rotor position corresponds to the instant shown in Fig. 2. The corresponding positive and negative degree positions represent the rotor rotating clockwise and anticlockwise, respectively.
According to the conduction waveforms shown in Fig. 4, all five-phase currents remain unchanged within an interval of $36^{\circ}$ only. Therefore, the torque variation between $-18^{\circ}$ and $18^{\circ}$ can be used to evaluate the idealized steady-state torque pulsation. To assess this torque pulsation, a torque ripple ratio is defined as

$$
C_{r}=\frac{T_{\max }-T_{\min }}{T_{a v}} \times 100 \%,
$$

where $T_{\max }, T_{\min }$, and $T_{a v}$ represent the maximum torque, the minimum torque, and the average torque, respectively. Based on Fig. 7(a) and (18), various values of $C_{r}$ for different phase currents are calculated and listed in Table I. It should be noted that the torque ripple ratio of the proposed motor is reasonable and similar to that of other PM brushless dc motors. 
TABLE I

TORQUE RIPPLE RATIO

\begin{tabular}{lllll}
\hline$I(\mathrm{~A})$ & 4.67 & 9.33 & 18.67 & 21.67 \\
$C_{r}(\%)$ & 14.02 & 12.13 & 13.45 & 12.12 \\
\hline
\end{tabular}

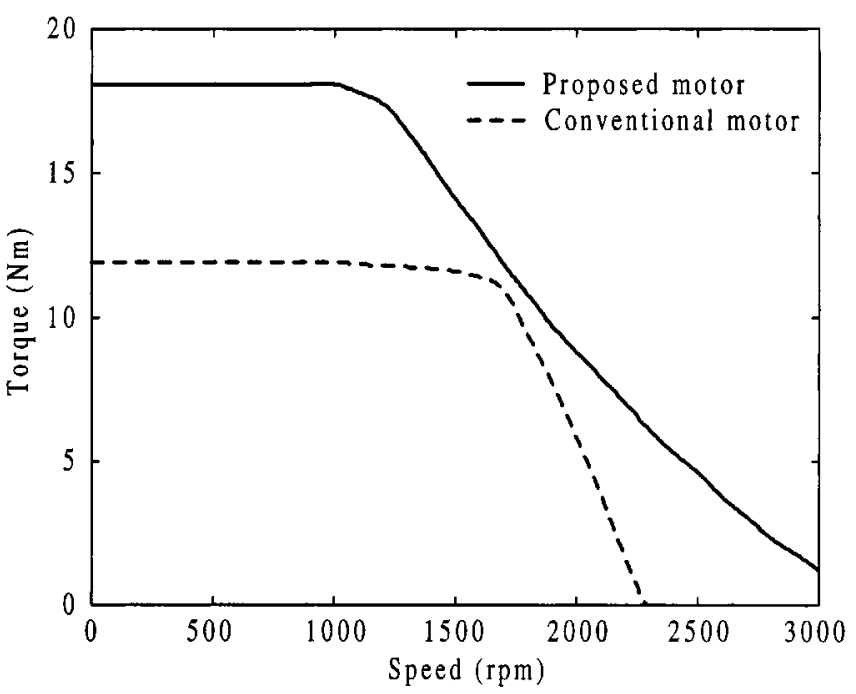

Fig. 8. Torque-speed characteristics.

Fig. 7(b) illustrates the variations of the torque and its two components with respect to the phase current. When the phase current is equal to the rated value of $21.67 \mathrm{~A}$, the PM torque takes up $64.8 \%$ of the total torque and the reluctance torque is of $35.2 \%$. The percentages of these torque components can be changed by varying the PM pole width during the design stage or the stator field current during the operational stage. On the other hand, Fig. 7(c) shows the normalized torque-current characteristics in which the total torque, the PM torque, the reluctance torque, and the phase current are normalized by their rated values, respectively. In this way, the variation of each torque component with respect to the phase current can be compared clearly. It can be found that because the normalized reluctance torque is approximately proportional to the square of the normalized phase current, it rises up faster than does the normalized PM torque. Particularly, at overcurrent start-up, this reluctance torque component can significantly improve the normalized total torque. Therefore, the proposed motor takes definite advantages of high-power density and high starting torque than do those available PM brushless dc motors. These merits are very essential for EV propulsion, which needs frequent start/stop and short acceleration time.

In order to illustrate the advantageous characteristics of the proposed motor drive, the corresponding torque-speed characteristic is compared with that of a conventional surface-mounted PM brushless dc motor drive that has the same PM poles. The comparison is based on computer simulation at the same current and voltage ratings. As shown in Fig. 8, the proposed motor drive can offer significantly higher torque at the constant torque region and significantly higher speed at the constant power region than does its conventional counterpart. The increases in both the torque capability and the speed range are due to the additional reluctance torque component.
TABLE II

MOTOR DATA

\begin{tabular}{ll}
\hline Rated power & $1.8 \mathrm{~kW}$ \\
Rated voltage & $2 \times 48 \mathrm{~V}$ \\
Rated speed & $1000 \mathrm{rpm}$ \\
Rated phase current & $21.67 \mathrm{~A}$ \\
Number of phases & 5 \\
Stator & $180 \mathrm{~mm}$ \\
Outer diameter & $110 \mathrm{~mm}$ \\
Inner diameter & $60 \mathrm{~mm}$ \\
Stack length & 30 \\
Number of slots & Single layer \\
Winding type & 15 \\
Number of coils & $5 \mathrm{slot}$ \\
Coil pitch & 18 \\
Turns per coil & $0.103 \Omega$ \\
Resistance per phase $\left(75^{\circ} \mathrm{C}\right)$ & \\
Rotor & $109 \mathrm{~mm}$ \\
Outer diameter & $63 \mathrm{~mm}$ \\
Inner diameter & 6 \\
Number of poles & $4.5 \mathrm{~mm}$ \\
Magnet height (maximum) & $26.4^{\circ}$ \\
Magnet width & $1.05 \mathrm{~T}$ \\
Magnet remanence & Nd-Fe-B \\
Magnet material & \\
\hline
\end{tabular}

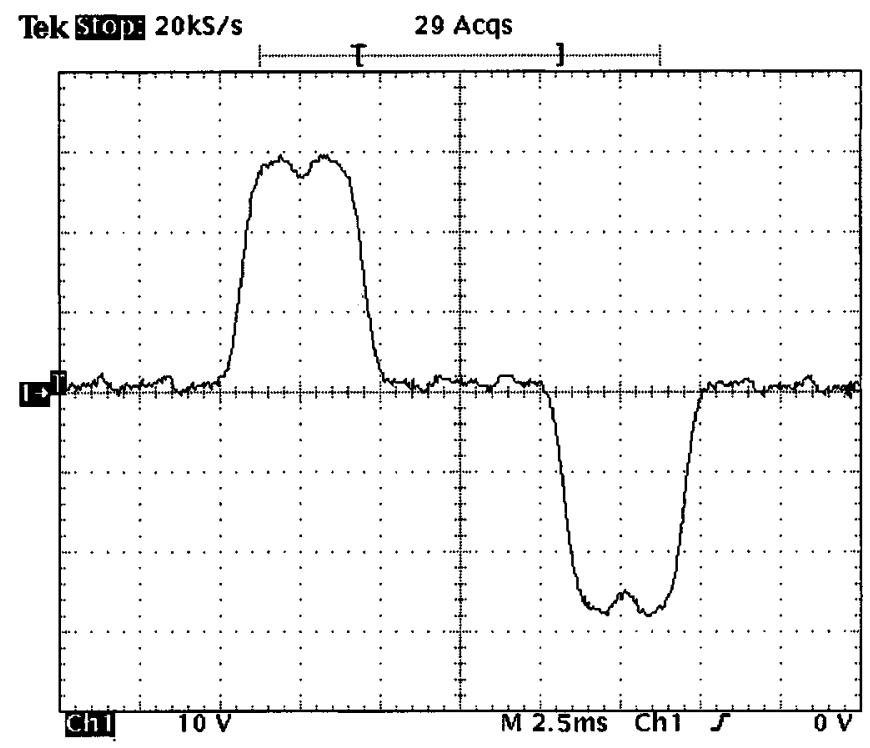

Fig. 9. Experimental waveform of no-load EMF (10 V/div, $2.5 \mathrm{~ms} / \mathrm{div})$.

\section{EXPERIMENTAL RESULTS}

A 1.8-kW prototype of the proposed motor has been built. The technical data of the motor is given in Table II. When the motor runs as a generator, the no-load EMF is measured. Fig. 9 shows the measured EMF waveform at the rated speed of $1000 \mathrm{rpm}$. It can be found that the measured waveform closely agrees with the theoretical waveform shown in Fig. 6(b). Hence, the validity of the theoretical results obtained from the FEM is verified. The measured system efficiencies of the proposed motor drive (including both the motor and the inverter) at the base speed of $1000 \mathrm{rpm}$ and the constant power operating speed of $3000 \mathrm{rpm}$ are $83.6 \%$ and $89.0 \%$, respectively. Such high efficiencies are comparable to those offered by any conventional PM brushless motor drives [4]. 


\section{CONCLUSION}

A new five-phase, surface-inset, PM brushless dc motor drive has been developed. Because of the multiphase windings in the stator and the unique geometry of PM poles in the rotor (the width of each PM pole equals about $2 / 5$ pole-pitch), the motor possesses advantageous characteristics of both the PM brushless dc motor and the dc series motor, namely, the powerful PM torque and the controllable reluctance torque (proportional to the square of the phase current). This new motor drive offers the merits of high-power density, high efficiency, high starting torque, wide adjustable speed range for constant power operation, and mechanical robustness. These merits make it very promising for modern EV propulsion.

\section{REFERENCES}

[1] C. C. Chan, "An overview of electric vehicle technology," IEEE Proc., vol. 81, pp. 1202-1213, 1993.

[2] T. M. Jahns, "Flux-weakening regime operation of an interior permanent magnet synchronous motor drive," IEEE Trans. Ind. Applicat., vol. 23, pp. 681-689, 1987.

[3] S. Morimoto, Y. Takeda, T. Hirasa, and K. Taniguchi, "Expansion of operating limits for permanent magnet motor by current vector control considering inverter capacity," IEEE Trans. Ind. Applicat., vol. 26, pp. 866-871, 1990.

[4] W. L. Soong and T. J. E. Miller, "Field-weakening performance of brushless synchronous AC motor drives," IEE Proc.-Electric Power Applicat., vol. 141, pp. 331-340, 1994.

[5] T. Sebastian and G. R. Slemon, "Operating limits of inverter-driven permanent magnet motor drives," IEEE Trans. Ind. Applicat., vol. 23, pp. 327-333, 1987.

[6] R. F. Schiferl and T. A. Lipo, "Power capability of salient pole permanent magnet synchronous motors in variable speed drive applications," IEEE Trans. Ind. Applicat., vol. 26, pp. 115-123, 1990.

[7] L. Xu, L. Ye, L. Zhen, and A. El-Antably, "A new design concept of permanent magnet machine for flux weakening operation," IEEE Trans. Ind. Applicat., vol. 31, pp. 373-376, 1995.

[8] C. C. Chan, J. Z. Jiang, W. Xia, and K. T. Chau, "Novel wide range speed control of permanent magnet brushless motor drive," IEEE Trans. Power Electron., vol. 10, pp. 539-546, 1995.

[9] C.C. Chan, J. Z. Jiang, G. H. Chen, X. Y. Wang, and K. T. Chau, "A novel polyphase multipole square-wave permanent magnet motor drive for electric vehicles," IEEE Trans. Ind. Applicat., vol. 30, pp. 1258-1266, 1994.

[10] H. Weh, H. Mosebach, and H. May, "Design concepts and force generation in inverter-fed synchronous machines with permanent magnet excitation," IEEE Trans. Magn., vol. 20, pp. 1756-1761, 1984.

[11] H. Weh and U. Schröder, "Static inverter concepts for multiphase machines with square-wave current-field distribution," in Proc. Eur. Power Electron. Conf., 1985, pp. 1147-1152.

[12] R. Mayer, H. Mosebach, U. Schröder, and H. Weh, "Inverter-fed multiphase reluctance machines with reduced armature reaction and improved power density," in Proc. Int. Conf. Electric. Machines, 1986, pp. $1138-1141$.

[13] J. D. Law, A. Chertok, and T. A. Lipo, "Design and performance of field regulated reluctance machine," IEEE Trans. Ind. Applicat., vol. 30, pp. 1185-1192, 1994.
[14] T. Sebstian and G. R. Slemon, "Modeling of permanent magnet synchronous motors," IEEE Trans. Magn., vol. 22, pp. 1069-1071, 1986.

[15] Z. Q. Zhu, D. Howe, and Z. P. Xia, "Prediction of open-circuit airgap field distribution in brushless machines having an inset permanent magnet rotor topology," IEEE Trans. Magn., vol. 30, pp. 98-107, 1994.

Jinyun Gan was born in Shanghai, China, in 1966. He received the B. Sc. (Eng.) and M. Sc. (Eng.) degrees in electrical engineering from Shanghai University of Technology in 1986 and 1990, respectively. He is currently pursuing the Ph.D. degree from the Department of Electrical and Electronic Engineering, The University of Hong Kong.

Prior to entering the Ph.D. program, he was a Lecturer with the School of Automation, Shanghai University. His research interests include advanced permanent magnet motor drives, motor drive system analysis and design, power electronics, and electric vehicles. He has published about 10 technical papers, and is the corecipient of two Chinese patents within these fields.

K. T. Chau (M'89) received first-class honors B. Sc. (Eng.), M. Phil., and Ph.D. degrees in electrical and electronic engineering from the University of Hong Kong.

Currently, he works as an Associate Professor at the University of Hong Kong. His teaching and research interests focus on three main areas: power converters, machines and drives, and electric vehicles. In these areas, he has published more than 100 refereed technical papers and some industrial reports.

Dr. Chau has served as chair and organizing committee member for many international conferences. His biography is listed in Who's Who in Science and Engineering 1998-1999.

C. C. Chan (M'77-SM'77-F'92) received the B.Sc. degree from China University of Mining and Technology, Beijing, China, the M.Sc. degree from Tsinghua University, Beijing, China, and the Ph.D. degree from University of Hong Kong, in 1953, 1957, and 1981, respectively, and he was awarded the Honorary D.Sc. degree from the University of Odessa in 1992.

He is currently the Head and Chair Professor of Electrical Engineering in the Department of Electrical and Electronic Engineering, University of Hong Kong. He has authored four books, published more than 120 technical papers, and holds seven patents.

Dr. Chan is a Fellow of the Royal Academy of Engineering, U.K., an Academician of the Chinese Academy of Engineering, and a Fellow of the Ukraine Academy of Engineering Science.

J. Z. Jiang was born in Jiangsu, China, on October 11, 1939. He received the B.E.E. and M.E.E. degrees from Shanghai Jiao-Tong University in 1962 and 1965, respectively, and the Dr.-Ing. degree from the Technical University of Braunschweig, Germany, in 1988.

$\mathrm{He}$ is a Professor of Electrical Engineering at Shanghai University. His research interests include high-performance variable-speed drives, electric machine design, numerical analysis of electromagnetic field in electric machinery, the dynamic modeling of machines, and their associated power electronics. He has published more than 30 papers, and he has two patents in these fields. 